\title{
Inventory of uncertainties associated with the process of tsunami damage assessment on buildings (SCHEMA FP6 EC co-funded project)
}

\author{
A. Gardi ${ }^{1}$, N. Valencia ${ }^{1}$, R. Guillande ${ }^{1}$, and C. Andrée ${ }^{1, *}$ \\ ${ }^{1}$ Geosciences Consultants sarl, Paris, France \\ *now at: Université de Bretagne Occidentale, Brest, France
}

Received: 16 September 2010 - Revised: 5 January 2011 - Accepted: 10 January 2011 - Published: 18 March 2011

\begin{abstract}
Within the framework of the SCHEMA FP6 EC co-funded project (http://www.schemaproject.org), we have identified the sources of errors/uncertainties that can be introduced at several steps of the damage assessment process, from post-disaster field measures up to hazard and damages maps production. Errors, for instance, are introduced when collecting post-disaster observations owing to different types of instruments/methods, water marks considered, tide correction, etc.: in extreme cases, differences of meters can be found between water heights data published by different teams for the same locations. Much uncertainty comes from difficulties in identifying and characterizing the potential tsunami sources and from numerical modelling. Moreover, the resolution of the employed Digital Terrain Models can noticeably affect the predicted inundation extent. We have also verified that the consistency of the computations on the long term varies sensitively depending on the code, raising the problem of results reliability for emergency management in dangerous coasts exposed to repeated waves. In addition, damage assessment is performed using damage functions linking the mean damage level on buildings with the maximum water elevation measured in the field without considering other tsunami parameters such as stream velocity. Finally, we examined uncertainties introduced in hazard and vulnerability mapping due to cartographic processing.
\end{abstract}

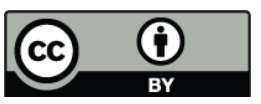

Correspondence to: A. Gardi (annalisa.gardi@gmail.com)

\section{Introduction}

According to their nature and origin, uncertainties can be classified as either aleatory (describing intrinsic variability of the physical process itself) or epistemic (related to a lack of knowledge). Aleatory uncertainties are irreducible whereas epistemic uncertainties, on the contrary, can be reduced through gaining knowledge, i.e. through the acquisition of additional and more accurate data.

Several studies exist in literature analysing the uncertainty in the field of tsunamis. These mainly focus on numerical modelling for the assessment of tsunami hazard: as a brief summary, Geist (2010) describes the type of uncertainties associated with computational models of how tsunamis are generated, how they travel through the ocean and what happens when they hit the coastlines. The variation (uncertainty) in the output of a numerical model can be apportioned, qualitatively or quantitatively, through a sensitivity analysis, to different sources of variation in the input of the model. The publications about this type of analysis are numerous (e.g., Weisz and Winter, 2005; Grilli et al., 2007; Dao and Tkalich, 2007; Synolakis et al., 2007; Hébert et al., 2007).

Often, uncertainty analyses are conducted with the aim of improving the accuracy of tsunami forecasts and early warning (Geist et al., 2007; Behrens et al., 2008, 2010). It is important to clarify that the work presented here has not been carried out in this framework, and that it does not have the ambition of performing an exhaustive uncertainty analysis: our goal is simply to highlight that the maps of expected damages include uncertainties coming from all the phases of their creation (from the data acquired during post-disaster survey and used to develop damage functions, through the characteristics of the sources chosen for the hazard assessment, the numerical simulations, up to the vulnerability assessment studies and the final cartographic processing). As it is not

Published by Copernicus Publications on behalf of the European Geosciences Union. 
possible to quantify the influence of all these uncertainties on the final damage maps, an inventory and tentative classification have been carried out and are presented in this paper.

As detailed further, a few examples to illustrate some sources of uncertainties are taken from the first results of the on-going French "MAREMOTI" project. Nevertheless, the work presented here has been mainly realized within the frame of the FP6 European co-funded project SCHEMA (SCenarios of Hazard-induced Emergencies MAnagement). The objective of this latter project was to develop a general methodology, with the employment of Earth Observation data, for the production of tsunami scenarios and vulnerability and damages maps, based on intrinsic variables of the stakes, spatio-temporal variables and organizational vulnerability variables, which determine the efficiency of warning and rescue operations. The impact of the Indian Ocean tsunami of December 2004 in Banda Aceh, Sri Lanka and the Seychelles has been used as a study case for extracting all the relevant information for vulnerability, hazard and crisis management factors. The developed methodology has been tested on five pilot sites located in NE Atlantic (Morocco and Portugal), Mediterranean (France and Italy) and Black Seas (Bulgaria) and validated with local end-users. It is during the realization of the SCHEMA project that we had to deal with, and thus we could identify and examine, the different sources of the uncertainty affecting the tsunami expecteddamage maps.

\section{The SCHEMA approach}

The methodology developed within the framework of SCHEMA for the production of tsunami scenarios and the assessment of impact on exposed coasts is going to be presented in details in a handbook, edited by JRC, Ispra (Joint Research Centre, European Commission), which is actually under preparation and will be published in the beginning of 2011. Here, we are going only to present the concept and the principal phases and products of the general approach developed by the SCHEMA Consortium.

This methodology of SCHEMA project consists in the following steps:

Step 1: definition of a number of credible worst-case scenarios. The work starts with the identification of the tsunami sources (remote and local) capable of producing the most important effects on the area of interest. The choice of the sources and of their characteristics is based on tectonic considerations and on the known historical records.

Step 2: building computational grids. The tsunami simulations to be performed need a set of nested grids with increasing resolution. Accurate local bathymetry and topography data sets thus have to be used to build fine resolution grids covering the regions of interest.

Step 3: tsunami simulations. Numerical modelling is carried out computing the tsunami generation and propagation from each of the selected sources to the region of interest, and then the inundation in the target area.

Step 4: production of hazard scenarios. For each selected source, the results of the tsunami simulations are extracted and presented in such a way as to construct two types of hazard scenarios ("hazard" intended as the description of the physical phenomenon): the Regional Hazard Scenarios (more focused on tsunami propagation aspects and large scale coastal impact) and the Local Hazard Scenarios (more focused on the inundation aspects in the area of interest). A regional hazard scenario contains maps of: arrival times of first waves, instantaneous water elevation at selected propagation times, maximum and minimum water elevation (on a large scale), and synthetic tide gauges in some selected points. A local hazard scenario, on the contrary, contains maps with the maximum inundation extent (floodable zone limit), the maximum water elevation and flow depth in the affected zone, maximum receding level (i.e., minimum water elevation), and maximum current speed (offshore and onshore). All the computed scenarios can be synthesised into a unique scenario by performing an "aggregation": this means that for each computed field (water elevation for example), the maximum value among all the scenarios is considered in each point of the grid. This will produce a water elevation map which gives, in each point, the worst-case value.

Step 5: analysis of the damages produced by the computed tsunami. An intense study of the region of interest is carried out by Earth Observation or field survey in order to identify the level of vulnerability of exposed elements, e.g. the vulnerability class of exposed buildings (or roads, or bridges, etc.) following for example the typology proposed by Valencia et al. (2011). Once the buildings inventory and classification has been completed, it is possible to cross this with the modelled maximum flow depths in order to allocate a maximum expected flow depth for each building of the data base. Then, ad-hoc damage functions can be used to predict the level of damage expected for each building depending on its vulnerability and on the maximum flow depth. This procedure is realized on GIS: once the inundation maps and building classes map have been produced, they can be crossed with the damage matrix (obtained by discretization of damage functions) in order to produce the Local Damage Scenario map. This last one can be finally enriched by the additional mapping of secondary vulnerability criteria (e.g. soil type, age of buildings, orientation, presence of potential floating objects such as cars or boats, etc.).

Uncertainties intervene at all stages and at several levels in the entire process, as detailed in the following sections, starting from the collection of post-disaster observations necessary for the development of damage functions up to the production of expected damages maps. 
Table 1. Summary of the three analyzed field surveys which were conducted in Banda Aceh (Indonesia) after the December 2004, Indian Ocean tsunami.

\begin{tabular}{|c|c|c|c|c|}
\hline $\begin{array}{l}\text { Team* } \\
\text { Date of field survey } \\
\text { (References) }\end{array}$ & Type of water mark & Referential & $\begin{array}{l}\text { Field } \\
\text { measurement }\end{array}$ & Correction for tides \\
\hline $\begin{array}{l}\text { Y. Tsuji } \\
\text { Jan } 2005 \\
\text { (Tsuji et al., 2005) }\end{array}$ & $\begin{array}{l}\text { Several water marks } \\
\text { (due to different waves } \\
\text { and sea receding) }\end{array}$ & Mean sea level & Water elevation & $\begin{array}{l}\text { Effects of the } \\
\text { astronomical tide } \\
\text { are removed }\end{array}$ \\
\hline $\begin{array}{l}\text { J. C. Borrero } \\
\text { Jan } 2005 \\
\text { (Borrero, 2005a, b; } \\
\text { Borrero et al., 2006) }\end{array}$ & $\begin{array}{l}\text { Water marks } \\
\text { on the sea side }\end{array}$ & Ground & Flow depth & $\begin{array}{l}\text { Tide level at the } \\
\text { time of the event }\end{array}$ \\
\hline $\begin{array}{l}\text { Tsunarisque } \\
\text { Jan and Aug 2005, } \\
\text { Aug } 2006 \\
\text { (Lavigne et al., 2009) }\end{array}$ & Highest water marks & $\begin{array}{l}\text { Ground and tide } \\
\text { level at the time } \\
\text { of the event }\end{array}$ & $\begin{array}{l}\text { Flow depth and } \\
\text { water elevation }\end{array}$ & $\begin{array}{l}\text { Tide level at the } \\
\text { time of the event }\end{array}$ \\
\hline
\end{tabular}

* Team leader or name of the project

\section{Post disaster observations}

During field surveys, when collecting post disaster observations, errors are introduced owing to different measuring methods: type of instruments used, type of water marks taken into account, referential (sea level or ground), type of correction applied for tides.

For the purposes of the SCHEMA project, and in particular for the development of new damage functions (Valencia et al., 2011), three data bases of water height measurements collected in Banda Aceh (Indonesia) after the Boxing Day 2004 event by three different teams have been analysed and compared in detail. Table 1 resumes the characteristics of the three analyzed field surveys conducted by a Japanese team (Tsuji et al., 2005), the International Tsunami Survey Team (Borrero, 2005a, b) and a French \& Indonesian team (Lavigne et al., 2009) in the beginning of 2005. The data are available on the Internet and/or in scientific publications. Since the three teams did not refer to the same referential level and did not apply the same tide corrections, their measurements can not be directly compared to each other and some modifications are necessary to make the datasets comparable.

In the field, several types of indicators of inundation levels can be observed, such as debris, water marks on buildings, floating objects and sand deposited on upper floors or roofs, etc. These give the maximum vertical elevation of the flow and can be measured either with respect to the sea level on the day of the measurement or with respect to the ground level. If the height of the water marks is measured with respect to the sea level at the time of the measurement, a correction must be applied for tides in order to bring the measurement to the sea level at the time of the tsunami's occurrence or to the mean sea level (thus obtaining what is called by Tsuji et al., 2005, the "pure tsunami heights", i.e. the absolute water elevation above mean sea level). On the contrary, if the height of the indicator is measured with respect to the ground level (giving the so-called "flow depth"), it can be converted into a "pure tsunami height" by subtracting the local value of the Digital Terrain Model at the point of the measure.

The Japanese team leaded by Y. Tsuji presented its observations under the form of pure tsunami heights, thus with respect to the mean sea level (Tsuji et al., 2005). On the contrary, Borrero (2005a, b) measured essentially the flow depth (i.e., water level from ground), whereas the Tsunarisque team has considered in some cases the flow depth and in others the water elevation with respect to the sea level at the time of the measurement and they performed conversions in order to present their database with the two types of measurements at all the locations of their survey.

In order to make all these different observations comparable, it was necessary to tie all of them to the same base line. In our case, we chose to compare the flow depths. To perform the necessary conversions, we made use of the $18 \mathrm{~m}$ gridsize DTM of Banda Aceh created in the framework of the TSUNARISQUE program (Lavigne et al., 2009) and modified by the CEA/DASE (Commissariat à l'Energie Atomique - Loevenbruck et al., 2007).

Comparing the results of the three data sets of observations (Fig. 1), we notice important differences between them: while data by Borrero (2005a, b; squared symbols in Fig. 1) and Tsuji et al. (2005; triangles in Fig. 1) are quite consistent, values from Tsunarisque (Lavigne et al., 2009; represented by stars in Fig. 1) are significantly higher, in some locations even double the other measurements. This can not be ascribed to topographic variations, since in this area the terrain 


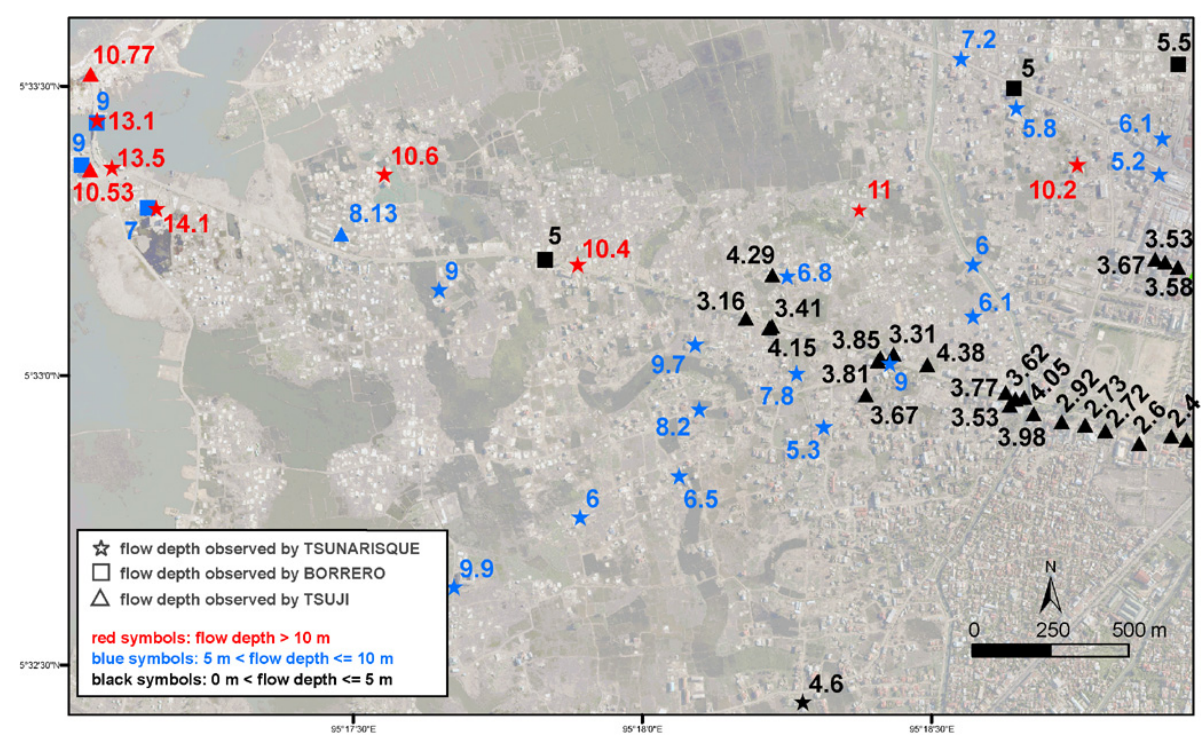

Fig. 1. Comparison between the flow depth data collected in Banda Aceh (Indonesia) by the three different teams presented in Table 1 . Colours give the depth ranges (red: flow depth $>10 \mathrm{~m}$; blue: $5 \mathrm{~m}<$ flow depth $\leq 10 \mathrm{~m}$; black: flow depth $\leq 5 \mathrm{~m}$ ).

is quite flat, very gradually increasing from $0 \mathrm{~m}$ on the left side of Fig. 1 to 3-4 m towards the bottom, right-hand corner of the figure.

Trying to find an explanation for these important discrepancies, we understood that the Tsunarisque team measured the highest visible water marks in each point (R. Paris, personal communication), while it seems that Borrero considered marks at levels less than the peak water heights (see their preliminary report, under the reference Borrero, 2005). Concerning the Tsuji team, we found in a report available on the internet (Kawata et al., 2005) that the authors sometimes measured several water marks visible on the same building, which could have corresponded to the arrival of several waves, or measures relative to the sea's recession (for constructing Fig. 1, we retained only the highest one for each point, in order to keep only the values linked to the arrival of the tsunami). This comparison exercise highlights the fact that operators in the field have to deal with a very complex set of water indicators. It also underlines the importance of always clearly indicating, in the same publications presenting the data, the choice made by an operator or a measurement team concerning the type of watermarks taken into account.

Additionally, errors or uncertainty are associated with the process employed, as described above, for the conversions between the different referential levels: the values taken for the tide corrections and the accuracy of the DTM used for passing from flow depths to water elevations and vice-versa. In our case, we could verify that the DTM we used for our conversions shows local differences of $15-20 \mathrm{~cm}$ with the ground elevation values appearing in the Tsunarisque database.
Errors in measurements can be also introduced due to the difficulty of interpreting field evidence. This has been highlighted indeed by Borrero et al. (2006), who remind us that it is easy to misinterpret debris and strand lines and that often it is essential to corroborate the observations by interviewing eyewitnesses.

In conclusion, the authors presenting field observations should always give clear information about the type of watermarks taken into account (maximum, minimum, others), the type of measurements performed and instruments used, the type of tide correction adding, if possible, an estimation of the error introduced due to the choice of the tsunami arrival time used for the tide correction (as done e.g. by Jaffe et al., 2006), the spatial resolution and accuracy of the DTM employed for conversions. When these details are missing, it is impossible for a reader to discriminate between the different types of measurements and to know the level of confidence of the observations. Thus the data observed in the field should be taken with a great caution, especially if they are needed for constraining numerical models.

\section{Numerical modelling and hazard mapping}

Numerous studies exist in literature about tsunami modelling and the influence that various parameters and phenomena have on the simulation results. Among others, an example is the work of Leschka et al. (2009), who studied the influence of nearshore bathymetry data quality on tsunami runup modelling; Weisz and Winter (2005), who showed the influence of the change of depth caused by tides; Grilli et al. (2007), who compared different numerical solutions. 
Table 2. Resolution of the bathymetry data sets used during the benchmarking of 5 different modelling tools presented in Sect. 3.1 and Fig. 2: COMMIT (Cornell University), MOHID (MARETEC, Lisbon, Portugal), GEOWAVE (Watts et al., 2003), TIDAL (ACRi Software Tools), UBO-TSUFD (Tsunami Research Team of the University of Bologna, Italy).

\begin{tabular}{lc}
\hline Simulation code & Finest bathymetric spatial resolution \\
\hline COMMIT & $30 \mathrm{~m}$ \\
MOHID & $30 \mathrm{~m}$ \\
GEOWAVE & $220 \mathrm{~m}$ \\
TIDAL & $90 \mathrm{~m}$ \\
UBO-TSUFD & $30 \mathrm{~m}$ \\
\hline
\end{tabular}

In the following sections, we will focus on two aspects of the tsunami modelling phase: the duration of the simulated phenomenon and the spatial resolution of the used Digital Terrain Model (DTM).

\subsection{Uncertainty in the duration of modelled phenomenon}

A comparison of five different numerical tools against a common test site in the Seychelles has been performed during the first phase of the SCHEMA project (SCHEMA Consortium, 2007). This allowed identifying limitations and uncertainties of numerical modelling for reproducing the tsunami propagation and inundation inland.

In particular, an interesting point concerns the duration of the modelled phenomenon: the benchmarking exercise of five different numerical tools led us to verify that the consistency of the computations on the long term varies sensitively depending on the code. This is particularly evident observing the synthetic tide gauges reported in Fig. 2, obtained by modelling the impact of the December 2004 tsunami onto the coast of Mahé island (Seychelles): apart from evident discrepancies between several results in terms of period and amplitude of the wave (owing also to the use of different spatial resolution DTMs, as detailed in Table 2), it is noteworthy that some of the simulated tide gauges show maximum waves three hours after the first one. Even if this can be really observed, as occurred e.g. in San Diego, where the largest wave amplitude of the 2010 Chilean tsunami was recorded more than five hours after the first wave arrival (Geist, 2010), the record of the Boxing Day 2004 tsunami from the tide gauge in Mahé does not show this characteristics (Fig. 2, bottom panel). It emerges that numerical simulations are not reliable anymore on the considered test site over the 5th or 6th peak corresponding nearly at three hours of calculation after the first wave's arrival time.

This raises the problem of the reliability of results for instance for emergency management in dangerous coastal

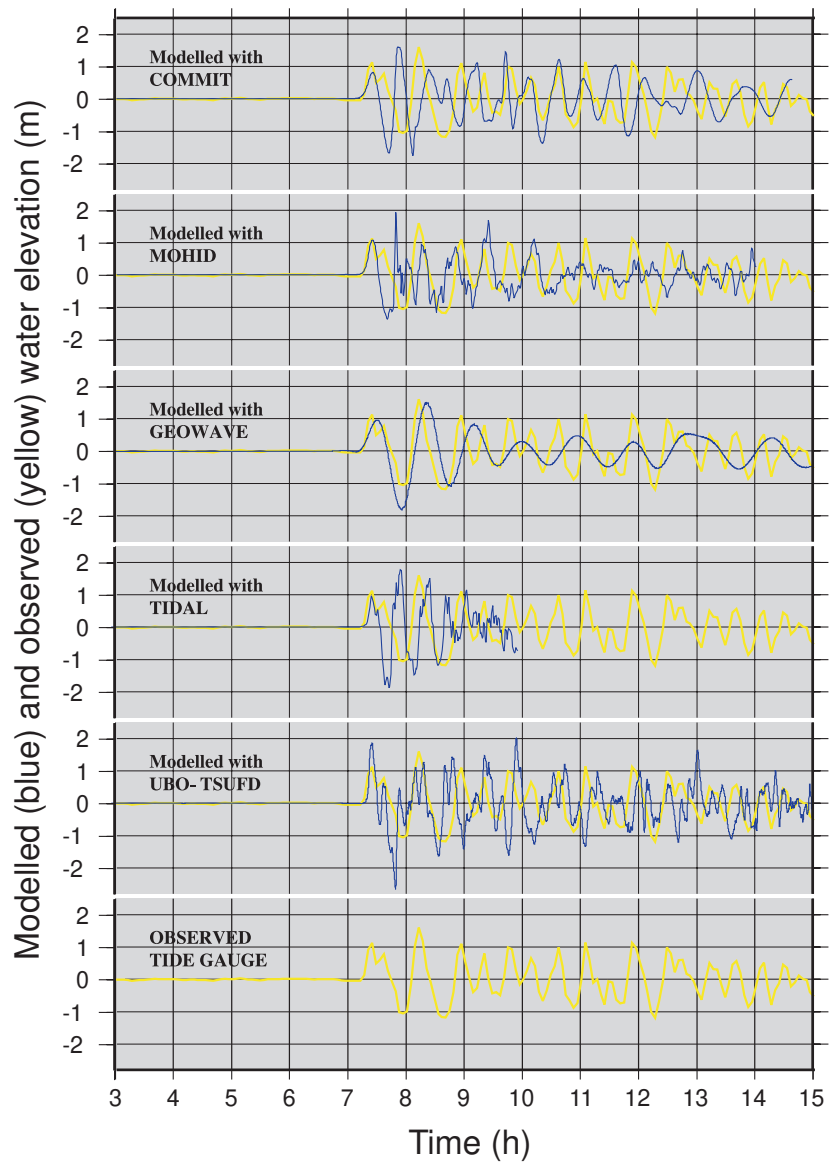

Fig. 2. Comparison between the real tide gauge recorded at Pointe La Rue (Mahé island, Seychelles) during the 26 December 2004 tsunami and different synthetic tide gauges generated by the numerical codes used in the framework of SCHEMA project (modified after SCHEMA Consortium, 2007). The first-wave arrival times of the synthetic signals have been fitted to the real one to make the comparison easier.

strips exposed to repeated waves, where rescue teams may have to work during several hours or days.

The limited reliability in the modelling results beyond the first waves are essentially related to the fact that the coastal response of tsunami waves is highly dependent on local bathymetry which may not be reliable enough in complex areas. This introduces some uncertainty, especially into the estimates of the maximum water elevation. For that reason, there should be an indication of time validity of modelling and a limit put to the peak waves to be considered when estimating the local inundation hazard. Not taking into consideration such a limit may lead to consider waves which may be artefact or only the results of model degeneration. 

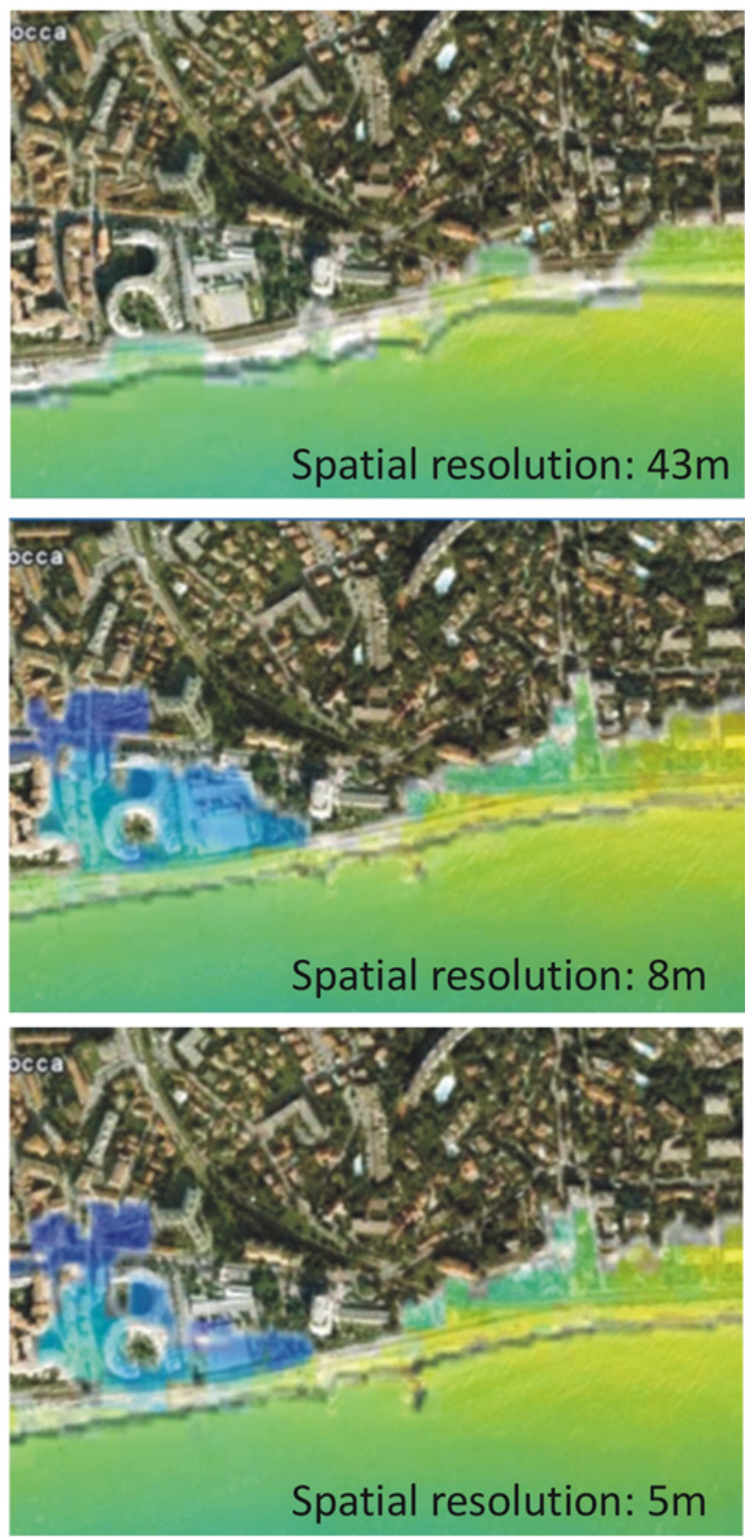

Fig. 3. Detail of the different inundations computed with the same initial conditions and input parameters, changing only the spatial resolution of the DTM (Cannes test site, south of France). Simulations have been performed with COMMIT (Cornell University), in the frame of the French ANR "MAREMOTI" project.

\subsection{Influence of Digital Terrain Models resolution}

Model predictions are particularly sensitive to the effects of local bathymetry and coastal topography that cause tsunami run-up to vary significantly, even in neighbouring areas.

A sensitivity study on the DTM resolution has been carried out in the framework of the ANR (French Research Agency)-funded project MAREMOTI. The chosen test site is the city of Cannes, on the Mediterranean coast of France. The study has been realized by means of the numerical code
COMCOT v7.1 (Cornell University). The DTM has been produced by a synthesis of several bathymetric (GEBCO, IFREMER, 1998 and 2004, SHOM()) and topographic data (Photogrammetry courtesy from the Cannes Municipality) and locally includes manual corrections introduced to ensure the taking into account of particular micro-structures (such as narrow dams, sea walls or banks in the harbour areas). The nested grids we constructed have an increasing resolution from $1800 \mathrm{~m}$ (this grid covers the western Mediterranean Sea), then $600 \mathrm{~m}, 200 \mathrm{~m}, 40 \mathrm{~m}$ up to $5 \mathrm{~m}$ in the inner grid, covering the city of Cannes. On this last grid, several tests have been performed with the horizontal resolutions $43 \mathrm{~m}$, $21 \mathrm{~m}, 8 \mathrm{~m}$ and $5 \mathrm{~m}$. All simulations have been performed with the same initial conditions and input parameters, the only factor changing being the resolution of the inner grid.

In this way, we could verify that locally, the extent of the modelled inundation can significantly depend on the DTM resolution, as shown in the results' samples depicted in Fig. 3: with the lowest resolution ( $43 \mathrm{~m}$, panel a) and owing to the topographic characteristics of the studied area (quite steep, with the first hills and little heights at only few tens of meters from the beach), the ground elevation in the cells of the grid along the coast lines is often overestimated, resulting in a lesser penetration of the inundation with respect to finest grids. In Fig. 3, as well, it can be noticed that even a difference of only $3 \mathrm{~m}$ in the spatial resolution can affect the results (panels $\mathrm{b}$ and $\mathrm{c}$ ) and that, with a $5 \mathrm{~m}$ resolution (panel c), the modelled inundation seems to better reflect the topographic details.

For better visualization of the differences between the results, Fig. 4 shows a vertical profile across a harbour bank. The three different DTMs $(43 \mathrm{~m}, 8 \mathrm{~m}$ and $5 \mathrm{~m})$ are depicted in this figure as well as the corresponding computed water levels. We choose to not apply any smoothing effect on the curves, in order to avoid any alteration and better appreciate the real differences between the computations. Looking at the three DTMs, it is noticeable that the coarse resolution of the $43 \mathrm{~m}$ DTM causes the vanishing of the bank feature. As a consequence, the whole area would appear inundated, even if the computed water level is almost identical to that computed uisng the other models. It is also interesting to note that slight differences exist between $8 \mathrm{~m}$ and $5 \mathrm{~m}$ DTMs, which explain the small variations in the mapped inundation (as already seen in Fig. 3), even though the computed water levels are the same.

The spatial resolution of the DTM grid, as well as its vertical accuracy (this one not investigated here), are thus at the origin of epistemic uncertainty in the estimates of the inundation extension. In order to obtain accurate inundation extensions, one should use DTM with a spatial resolution better than $10 \mathrm{~m}$, and if possible down to $5 \mathrm{~m}$. Vertical accuracy should be better than $1 \mathrm{~m}$ (e.g., Dall'Osso et al., 2010). 


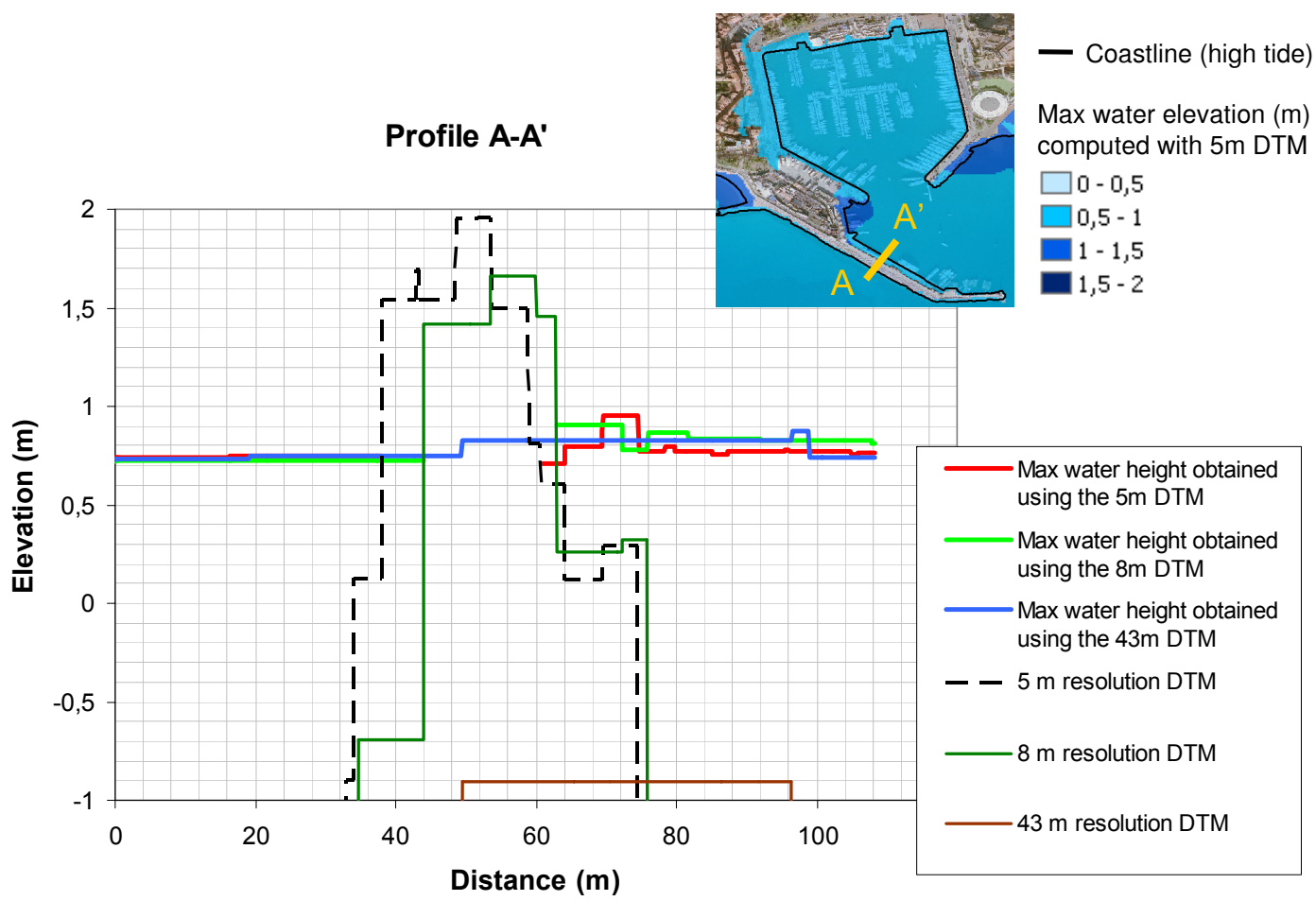

Fig. 4. Vertical profile across a bank of a Cannes (France) harbour.

\section{Damage assessment on buildings}

In the framework of SCHEMA, new damage functions (providing the expected level of damage on a building for a given flow depth) have been developed (Gauraz et al., 2009; Guillande et al., 2009; Valencia et al., 2011) based on the works by Leone et al. (2010) and Peiris (2006).

The data base on buildings and observed damage in Banda Aceh (Indonesia), acquired after the December 2004 event by Leone et al. (2006, 2010), has been extended by Valencia et al. (2011) by photo interpretation (using a satellite image taken before December 2004) and used to produce new damage functions for several types of buildings. The damage level on buildings has been linked to the maximum flow depth measured in the field, for each of the building classes. Figure 5 shows as an example the result of the analysis for the class B buildings (brick not-reinforced individual buildings). As it can be seen, error bars are quite large. The damage function has been deduced by the enveloping curve in order to take into account the most conservative option, i.e. the worst case.

Uncertainty is associated with several actions in the development of such functions, both in the creation of the initial database and during the development process itself, as resumed hereunder:
- Initial data base

- Observation and/or evaluation errors in the process of allocation of a vulnerability class to buildings by photo interpretation and field survey (classes A to $\mathrm{G}$, depending on the structural characteristics of resistance).

- Observation and/or evaluation errors in the process of allocation of a damage level (from D0, light damages, to D5, total collapse) to buildings by photo interpretation and field survey.

- Development of damage functions

- Uncertainty associated with the allocation of an inundation depth to each building.

- Creation of the functions by taking the maximum envelopping curves (overestimation of damage).

Uncertainty associated with observation or evaluation errors during the setting up of the initial database (allocation of vulnerability classes and damage levels to observed buildings) can be considered as aleatory, whereas uncertainties introduced during the development of damage functions could be reduced by the collection of additional data and are thus epistemic.

The developed damage functions link the damage level to the only reliable and uniform dimension of the tsunami which can be observed and measured after all events: the 


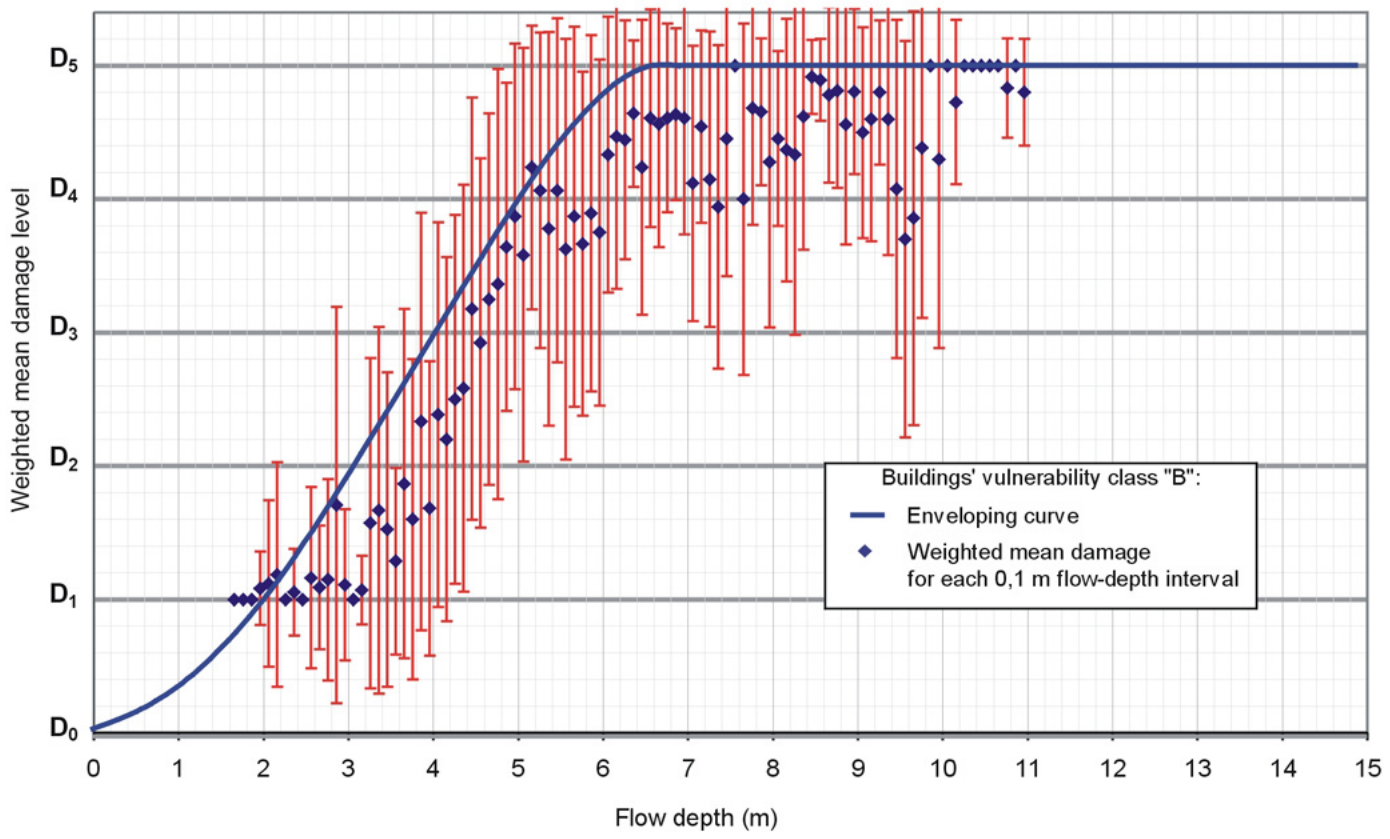

Fig. 5. Developed damage curve for class B (brick not-reinforced) buildings (Valencia et al., 2011). Error bars (in red) correspond to the dispersion around the mean damage for each water level, weighted on the total number of "B" buildings touched by the water level.

maximum flow depth. Therefore, they do not take into consideration other tsunami parameters such as the stream velocity.

Additional uncertainty is introduced because the damage functions have been empirically developed from data acquired where a very strong shake occurred before the tsunami attack, and thus can exhibit cumulated effects of both phenomena (tsunami and earthquake), even though the earthquake damage to structures in the area was reported to be minor (Borrero, 2005a, b). Finally, these functions implicitly integrate damage due to secondary factors such as erosion, impact by floating or dragged objects, etc.

The step that follows the creation of the damage curves is their discretization by thresholds to obtain a damage matrix, which facilitates the damage mapping by GIS. The way chosen for selecting the thresholds and discretizing the curve introduces further uncertainty. In SCHEMA, we opted also in this step for a maximization of the expected damages for each selected flow depth interval: in fact, the final damage maps are produced with the objective of helping managers to plan for the tsunami hazard in their region, and considering the most conservative solution was in line with the worst-case scenario approach followed within SCHEMA. This results of course in an overestimation of the expected damages.

\section{Cartography}

An additional crucial point, rarely mentioned, concerns the uncertainties introduced in hazard mapping due to cartographic processing.
As an example, we could check that an offset in the inundation maps can be due to a distortion of output raster maps or to resampling of the input DTM automatically operated by the numerical codes used for the tsunami simulation. Often this offset is less than 1 pixel, which can be acceptable for hazard mapping at regional level, but is more difficult to manage at a local scale for detailed vulnerability studies.

An example is shown in Fig. 6a, where we compare the $5 \mathrm{~m}$ DTM given as input to the COMCOT v7.1 (Cornell University) code and the DTM automatically resampled by the numerical code and used for the simulations. The offset is of about half a pixel, which can lead to biased information if the modelling results are analyzed by GIS superposing them to the input DTM. A general recommendation is thus to always use the DTM resampled by the numerical code, especially when producing detailed vulnerability or damages maps.

Figure $6 \mathrm{~b}$ highlights another interesting aspect of the GIS processing encountered using the ArcGIS package: converting the data (e.g. the computed water height) from point to raster, it is possible to obtain the curious result depicted in Fig. 6b, where an important offset exists between the original points and the corresponding pixel. This happens when the resampling operated by the numerical code does not generate a grid with uniform spacing: the results of the simulations are computed on this non-uniform grid, but ArcGIS generates its raster basing on a fixed distance step.

A noteworthy influence on fine hazard mapping is also exerted by the algorithm chosen for the interpolation of the gridded results. An example is shown in Fig. 7: panel (a) depicts the ArcGIS representation of a computed inundation 


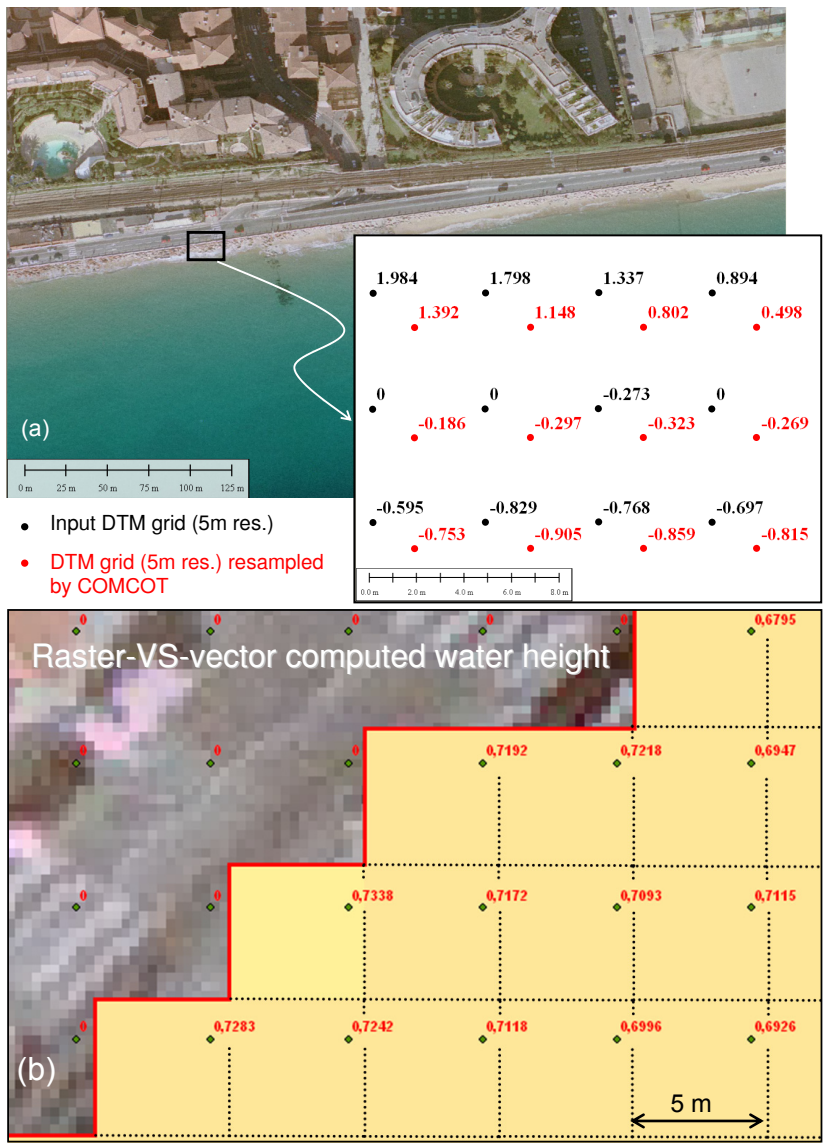

Fig. 6. (a) comparison between the DTM given as input to the numerical code COMCOT (Cornell University) and the DTM automatically resampled by the same code; (b) comparison between the vector and raster modelled water height (raster performed by ArcGIS package).

by the resampling method Nearest Neighbour, while in panel (b), the same result is represented by a bilinear interpolation method. Even if the difference between the two inundation limits is quite low (less than $10 \mathrm{~m}$ ), in some particular locations this could be enough to change the predicted condition of a stake (as the road in Fig. 7) from not inundated to inundated.

\section{Discussion and conclusions}

This paper presents an inventory of the uncertainties affecting the maps of expected damage that can be produced by using the methodology developed in the framework of the SCHEMA project. The aspects on which we focused have been analysed and presented here following the logical order of the SCHEMA approach: from the post-disaster observations, through the tsunami modelling, the vulnerability and damages assessment, up to the cartographic processing of the results.
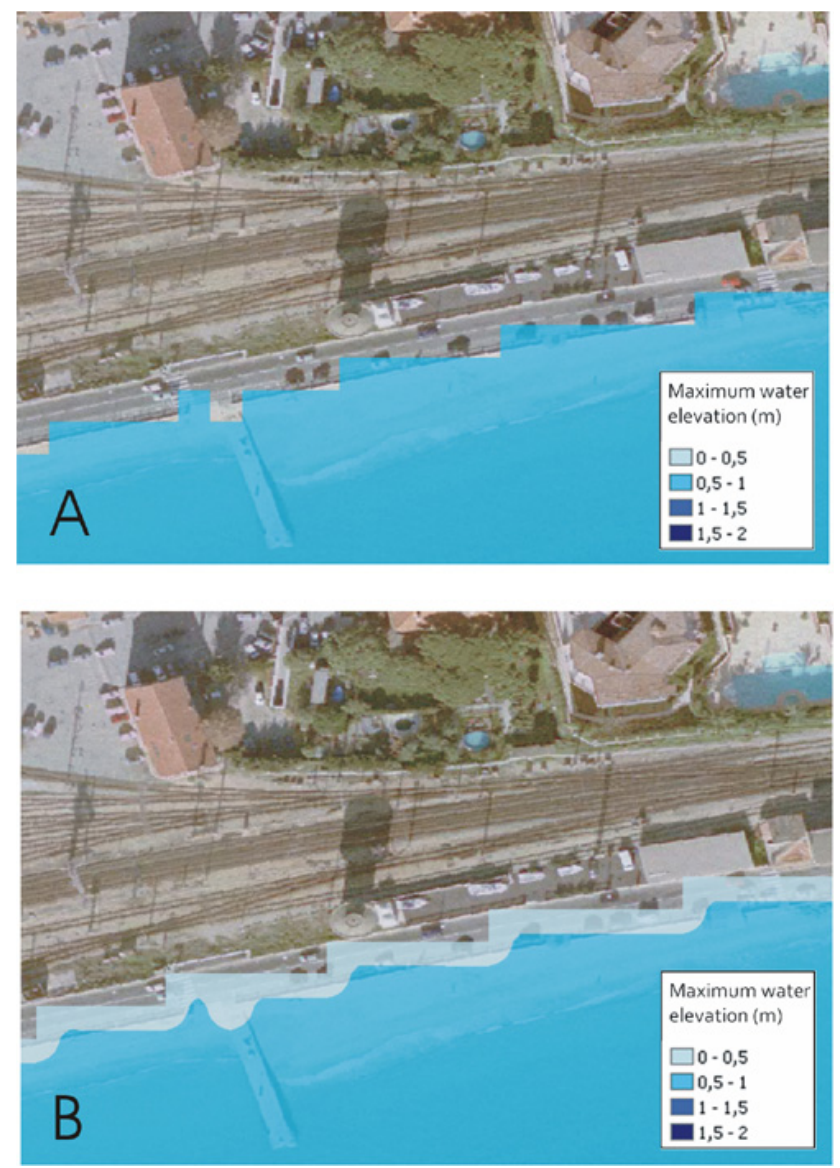

Fig. 7. Two possible representations (under ArcGIS) of the same computed inundation by using two resampling methods: nearest neighbour (A) or bilinear interpolation (B).

Uncertainty is introduced during the post-disaster field surveys due to different measuring methods, choice of referential level, space resolution of the DTM used for the conversions between the different types of measures (tsunami heights, flow depths). It is crucial that the authors presenting the collected field observations clearly indicate the type of measured water marks (maximum, minimum, others). Otherwise the readers could have to deal with seeming discrepancies of several meters between measurements of inundation heights published by different teams for the same locations.

The benchmarking of the numerical codes used in the framework of the SCHEMA project revealed, among other things, the difficulties of the codes in reproducing the expected attenuation of the phenomenon with time. Some of the tested codes obtained very high waves even several hours after the first wave arrival, in disagreement with the observations. This highlights the importance of assessing the maximum valid time laps after the first wave arrival for each code and each model and it raises the problem of reliability of these results for emergency management, because rescue teams may have to work through hours or days in the 
dangerous coastal stripes exposed to repeated waves. In order to limit the uncertainty, it is suitable, when producing hazard maps, to always include synthetic tide gauges, offshore and coastal, for each simulated scenario. This will clearly show if high waves are obtained by the modelling tool several hours after the first wave and will help in detecting numerical artefacts.

The influence of microstructures on inundation inland has been also investigated, within the framework of the French MAREMOTI project, by performing a sensitivity study of the modelling to the spatial resolution of the DTM, from $43 \mathrm{~m}$ down to $5 \mathrm{~m}$. It emerges that the modelled inundation is highly dependent on the DTM resolution, and that even differences of only $3 \mathrm{~m}$ in the pixel size can affect the results. This is particularly important in the case of inundation predictions to be used for detailed vulnerability and damages analyses.

Concerning the vulnerability and damage assessment phase, the uncertainty associated with the development of damage functions has been studied. The functions developed and used within the SCHEMA project (expressing the damage level expected on buildings for given flow depths) have been constructed from data acquired in areas where a very strong shake occurred before the tsunami attack and can thus exhibit the cumulated effects of both phenomena. They also integrate effects of secondary damaging factors such as erosion or impact of floating objects. Uncertainties intervene at different stages of their development and can only partially be quantified. Moreover, damage functions are built linking the damage level on buildings to the maximum water elevation measured in the field, thus not taking into account tsunami-specific parameters such as the stream velocity.

A last critical point concerns the uncertainties introduced in the hazard mapping due to cartographic processing (interpolation algorithms, resampling, distorsion) and to the resolution of the input DTM used for numerical simulations. In order to optimize inundation maps and hazard and vulnerability mapping, a general recommendation is to use very fine DTMs (grid spacing less than $10 \mathrm{~m}$, better if down to $5 \mathrm{~m}$ ) and to avoid any smoothing during the graphical processing of the results as much as possible.

Acknowledgements. We thank F. Lavigne and H. Hébert for providing us with the DTM of Banda Aceh. This work has been co-funded by the European Commission within the framework of the SCHEMA project (contract nr. SST5-CT-2006-030963) and by the French Research Agency (ANR) within the frame of MAREMOTI project, under the contract nr. ANR-08-RISK-506. Some figures were created using the Generic Mapping Tools software (Wessel and Smith, 1991). The use of bathymetric data by SHOM (C) Copyright 2008 Service Hydrographique et Ocanographique de la Marine - France) has been authorised by the Contract no. S/1314 BP. The constructive comments from two anonymous reviewers helped significantly to improve the manuscript.
Edited by: S. Monserrat

Reviewed by: two anonymous referees

\section{References}

Behrens, J., Klaschka, F., Mentrup, L., Raape, U., Strobl, C., Tessmann, S., and Riedlinger, T.: Handling uncertainty in tsunami early warning: interaction between decision support and multisensor simulation system. Proceedings of Int. Conf. on Tsunami Warning (ICTW), Bali, Indonesia, 12-14 November 2008.

Behrens, J., Androsov, A., Babeyko, A. Y., Harig, S., Klaschka, F., and Mentrup, L.: A new multi-sensor approach to simulation assisted tsunami early warning, Nat. Hazards Earth Syst. Sci., 10, 1085-1100, doi:10.5194/nhess-10-1085-2010, 2010.

Borrero, J. C.: Field data and satellite imagery of the tsunami effects in Banda Aceh, Science, 308, 1596, 2005a.

Borrero, J. C.: Field survey of northern Sumatra and Banda Aceh, Indonesia after the tsunami and earthquake of 26 December 2004, Seismol. Res. Lett., 76(3), 312-320, 2005 b.

Borrero, J. C., Synolakis, C. E., and Fritz, H. M.: Field surveys of northern Sumatra after the tsunami and earthquake of 26 December 2004, Earthquake Spectra, 22(S3), 93-104, 2006.

Dall'Osso, F., Maramai, A., Graziani, L., Brizuela, B., Cavalletti, A., Gonella, M., and Tinti, S.: Applying and validating the PTVA-3 Model at the Aeolian Islands, Italy: assessment of the vulnerability of buildings to tsunamis, Nat. Hazards Earth Syst. Sci., 10, 1547-1562, doi:10.5194/nhess-10-1547-2010, 2010.

Dao, M. H. and Tkalich, P.: Tsunami propagation modelling a sensitivity study, Nat. Hazards Earth Syst. Sci., 7, 741-754, doi:10.5194/nhess-7-741-2007, 2007.

Gauraz, A. L., Valencia, N., Koscielny, M., Guillande, R., Gardi, A., Leone, F., and Salaün, T.: Tsunami damages assessment: vulnerability functions on buildings based on field and earth observation survey, Geophysical Research Abstracts, vol. 11, EGU20095785, EGU General Assembly, Vienna (Austria), 2009.

Geist, E.: The Chilean tsunami and uncertainty in tsunami modelling, in: USGS Sound Waves monthly newsletter, available at: http://soundwaves.usgs.gov/2010/04/research2.html, 2010.

Geist, E., Titov, V. V., Kelly, A., and Gibbons, H.: TsunamiForecasting System Tested by Recent Subduction-Zone Earthquakes, in: USGS Sound Waves monthly newsletter, available at: http://soundwaves.usgs.gov/2007/04/research2.html, 2007.

Grilli, S. T., Ioualalen, M., Asavanant, J., Shi, F., Kirby, T. J., and Watts, P.: Source constraints and model simulation of the December 26, 2004 Indian Ocean Tsunami, ASCE J. Waterways, Port, Ocean and Coastal Engineering, 133(6), 414-428, 2007.

Guillande, R., Valencia, N., and Gardi, A.: Uncertainties in modelling and damage assessment of tsunami risk, implications for crisis management on Western Mediterranean coast (FP6 SCHEMA project), International Conference Provence' 2009, Seismic risk in moderate seismic area: from hazard to vulnerability, Aix-en-Provence (France), 6-8 July 2009.

Hébert, H., Sladen, A., and Schindelé, F.: Numerical Modeling of the Great 2004 Indian Ocean Tsunami: focus on the Mascarene Islands, Bull. Seismol. Soc. Am., 97(1A), S208-S222, doi:10.1785/0120050611, 2007.

IFREMER Editions: CA 98-01 Multibeam bathymetric data synthesis (occidental Mediterranean Sea), edited by: Normand, A. and Le Suavé, R.. 1/250 000 - 6 folded maps, undercovered, 1998. 
IFREMER Editions: CA 04-01 The gulf of Lyon, morphobathymetric map, edited by: Berné, S., Carré, D., Loubrieu, B., Mazé, J. P., Morvan, L., and Normand, A., 1/250 000 - 1 map, 2004.

Jaffe, B. E., Borrero, J. C., Prasetya, G. S., Peters, R., McAdoo, B., Gelfenbaum, G., Morton, R., Ruggiero, P., Higman, B., Dengler, L., Hidayat, R., Kingsley, E., Kongko, W., Lukijanto, Moore, A., Titov, V., and Yulianto, E.: Northwest Sumatra and Offshore Islands Field Survey after the December 2004 Indian Ocean Tsunami, Earthquake Spectra, 22, S3, S105-S135, 2006.

Kawata, Y., Tsuji, Y., Sugimoto, Y., Hayashi, H., Matsutomi, H., Okamura, Y., Hayashi, I., Kayane, H., Tanioka, Y., Fujima, K., Imamura, F., Matsuyama, M., Takahashi, T., Maki, N., and Koshimura, S.: Comprehensive analysis of the damage and its impact on coastal zones by the 2004 Indian Ocean tsunami disaster. Unpublished report, available at: www.tsunami.civil.tohoku. ac.jp/sumatra2004, 2005.

Lavigne, F., Paris, R., Grancher, D., Wassmer, P., Brunstein, D., Vautier, F., Leone, F., Flohic, F., De Coster, B., Gunawan, T., Gomez, Ch., Setiawan, A., Cahyadi, R., and Fachrizal: Reconstruction of tsunami inland propagation on December 26, 2004 in Banda Aceh, Indonesia, through field investigations, Pure Appl. Geophys., 166, 259-281, doi:10.1007/s00024-008-04318, database available at: www.tsunarisque.cnrs.fr/bd_tsuna.htm, 2009.

Leone, F., Denain, J. C., Vinet, F., and Bachri, S.: Analyse spatiale des dommages au bâti de Banda Aceh (Sumatra, Indonésie): contribution à la connaissance du phénomène et à l'élaboration de scénarios de risque tsunami, Scientific report of Tsunarisque (2005-2006) programme, 2006.

Leone, F., Lavigne, F., Paris, R., Denain, J. C., and Vinet, F.: A spatial analysis of the December 26th, 2004 tsunami-induced damages: Lessons learned for a better risk assessment integrating buildings vulnerability, Applied Geography, 31(1), 363-375, doi:10.1016/j.apgeog.2010.07.009, 2010.

Leschka, S., Kongko, W., and Larsen, O.: On the influence of the near shore bathymetry data quality on tsunami run-up modelling, PART II: Modelling, in: Proc. Of the 5th International Conference on Asian and Pacific Coasts (APAC2009), Singapore, edited by: Tan, S. K. and Huang, Z., 1, 157-163, 13-18 October 2009.
Loevenbruck, A., Hébert, H., Schindelé, F., Sladen, A., Lavigne, F., Brunstein, D., Wassmer P., and Paris, R.: Detailed Modeling of the 2004 Tsunami Flooding in the Banda Aceh and Lhok Nga Districts (Sumatra, Indonesia), Eos Trans. AGU, 88(52), Fall Meet. Suppl., Abstract S53A-1042, 2007.

Peiris, N.: Vulnerability functions for tsunami loss estimation. First European Conference on Earthquake Engineering and Seismology, Geneva, Switzerland, 2006.

SCHEMA Consortium: Lessons learned from Asia test sites. Scientific report nr. D1.3 of the European co-funded FP6 SCHEMA (Scenarios for Hazard-induced Emergencies MAnagement) project, available at: www.schemaproject.org/IMG/ pdf/SCHEMA_D1.3.pdf, 2007.

Synolakis, C. E., Bernard, E. N., Titov, V. V., Kânoğlu, U., and González, F. I.: Standards, criteria, and procedures for NOAA evaluation of tsunami numerical models, NOAA Technical Memorandum, OAR PMEL-135, 2007.

Tsuji, Y., Matsutomi, H., Tniaoka, Y., Nishimura, Y., Sakakiyama, T., Kamataki, T., Murakami, Y., Moore, A., and Gelfembaum, G.: Distribution of the tsunami heights of the 2004 Sumatra tsunami in Banda Aceh measured by the tsunami survey team Unpublished Internet report, http://www.eri.u-tokyo.ac.jp/ namegaya/sumatera/surveylog/eindex.htm, 2005.

Tsunarisque: Le tsunami du 26 décembre 2004 en Indonésie, Scientific report of the Tsunarisque (2005-2006) programme, 356 p., 2005.

Valencia, N., Gardi, A., Gauraz, A. L., Leone, F., and Guillande, R.: New tsunami damage functions developed in the framework of SCHEMA project: application to Euro-Mediterranean coasts, Nat. Hazards Earth Syst. Sci., in review, 2011.

Watts, P., Grilli, S. T., Kirby, J. T., Fryer, G. J., and Tappin, D. R.: Landslide tsunami case studies using a Boussinesq model and a fully nonlinear tsunami generation model, Nat. Hazards Earth Syst. Sci., 3, 391-402, doi:10.5194/nhess-3-391-2003, 2003.

Weisz, R. and Winter, C.: Tsunami, tides and run-up: a numerical study, in: Proceedings of the International Tsunami Symposium, edited by: Papadopoulos, G.A. and Satake, K., Chania, Greece, 322, 27-29 June 2005.

Wessel, P. and Smith, W. H. F.: Free software helps map and display data, EOS Trans. AGU, 72, 441, 1991. 